\title{
EFEITO DA SUPLEMENTAÇÃO COM FARELOS NO CRESCIMENTO IN VITRO DE PLEUROTUS OSTREATUS EM MEIOS À BASE DE CAPIM-ELEFANTE (PENNISETUM SPP.)
}

\section{L.P. Donini, E. Bernardi, E. Minotto, J.S. do Nascimento}

Universidade Federal de Pelotas, Instituto de Biologia, Departamento de Microbiologia e Parasitologia, Laboratório de Micologia, CP 354, CEP 96010-900, Pelotas, RS, Brasil. E-mail: lorenadonini@yahoo.com.br

\section{RESUMO}

\begin{abstract}
O cogumelo comestível Pleurotus spp. (hiratake) é cultivado em diferentes substratos lignocelulósicos, sendo que conforme a formulação do meio de cultivo, diferenças na produtividade poderão ser obtidas. Assim, este trabalho teve como objetivo avaliar o desenvolvimento in vitro de 3 linhagens de $P$. ostreatus, sob o efeito da suplementação de farelos em diferentes concentrações ao meio de cultura à base de capim-elefante. O experimento consistiu na utilização de meios de cultura estéreis à base de capim-elefante suplementados com farelos de soja, trigo, arroz e milho nas concentrações de 0,10 e $20 \%$, distribuídos em placas de Petri, inoculado com as linhagens BF24, DF33 e HF19 de $P$. ostreatus e incubados a $28^{\circ} \mathrm{C}$, visando a avaliação da biomassa fúngica e crescimento micelial. Verificou-se que o meio de cultivo com $20 \%$ de farelo de soja aumentou a biomassa fúngica e o crescimento micelial para as duas linhagens de P. ostreatus; a suplementação com farelo de trigo foi menos eficiente que a com farelo de soja e os farelos de arroz e milho não apresentaram efeito no aumento da biomassa fúngica e crescimento micelial das linhagens cultivadas.
\end{abstract}

PALAVRAS-CHAVE: Crescimento micelial, biomassa fúngica, suplementação, cogumelos, hiratake.

\section{ABSTRACT}

EFFECT OF SUPPLEMENT WITH BRANS ON THE IN-VITRO GROWTH OF PLEUROTUS OSTREATUS IN MEDIA MADE WITH ELEPHANT-GRASS (PENNISETUM SPP.). The edible mushroom Pleurotus spp. (hiratake) is cultivated in various lignocelullose-based substrates. Depending on the formulation of the medium, various levels of productivity are obtained. This research was therefore carried out to study the in-vitro development of $3 P$. ostreatus strains, cultured in elephant-grass culture media supplemented with soy, wheat, rice and corn bran at three different concentrations $(0,10$ and $20 \%)$. The cultures were incubated at $28^{\circ} \mathrm{C}$. Biomass and mycelium growth were evaluated. It was verified that the culture medium with $20 \%$ of soy bran increased the mycelium biomass and the mycelium growth for 2 of the $P$. ostreatus strains; wheat-bran supplement was less efficient than the soy bran, and the use of rice and corn bran did not result in an increase of the mycelium biomass and mycelium growth of the cultivated strains.

KEY WORDS: mycelium growth, mycelium biomass, supplement, mushroom, hiratake.

\section{INTRODUÇÃO}

O gênero Pleurotus pertence à ordem Agaricales e à família Agaricaceae, sendo amplamente distribuído mundialmente (EIRA \& MinHONI, 1997). Pleurotus sp. é encontrado, ocorrendonaturalmente tambémnas matas brasileiras, crescendo sobre madeira da qual retira nutrientes, provocando sua decomposição(MAZIEROet al., 1992; WisBECK, 2003; BonATTi et al., 2004).

O cultivo em módulo industrial de $P$. ostreatus teve início no final da segunda guerra mundial (Јов, 2004). No Brasil, o cultivo foi introduzido por volta de 1980, sendo utilizado o substrato bagaço de cana-de-açúcar, devido a sua abundância como resíduo da produção de álcool como combustível (MAZIERO et al., 1992). Espécies de Pleurotus são consideradas a segunda variedade de cogumelos mais produzidos no mundo (RAJARATHNAM et al., 2001).

Uma série de resíduos da agricultura como palhas de trigos, de arroz, gramíneas, serragens, polpa ecasca defrutas, folhas de bananeira, polpa decafé, bagaço de cana-de-açúcar entreoutros podem ser utilizados para produção de cogumelos comestíveis como oP.ostreatus (EIRA, 2003; MANDEEL et al., 2005; MODA et al., 2005). 
Na década de 1980, o aparecimento da técnica "Jun-Cao" (Jun = cogumelo, Cão = gramíneas), iniciada na China, em 1983, promoveu uma grande mudança no cultivo de cogumelos, unindo benefícios sociais, ecológicos e econômicos, além de estabelecer melhor equilíbrio ecológico entre plantas, fungos e animais (URBEN \& URIARTT, 2001). De acordo com estes mesmos autores ocapim-elefante (PennisetumpurpureumSchum) é uma das gramíneas indicadas para o cultivo de cogumelos através da técnica "Jun-Cao".

Segundo Silva (2004), muitos basidiomicetos desenvolvem-se em meios simples, que tenham disponibilidade de carbono assimilável, nitrogênio e fontes defósforo esais minerais necessários. Mas para meios formulados a partir do bagaço de cana-de-açúcar e palha de milho, a estes é preciso utilizar suplementação com outros materiais, contendo elementos essenciais para obtenção do crescimento do fungo. Além da utilização de resíduos como substratos, a suplementação destes com farelos como o de trigo e o de milho são comuns no cultivo deP. ostreatus(WANG et al., 2001). De acordo com Rossi et al. (2001), farelos de arroz e soja são fontes de nutrientes utilizadas como suplemento, pois estimula o crescimento miceliano de diversas espécies de cogumelo.

A capacidade do fungo crescer e produzir cogumelos em substratos lignocelulósicos está relacionada com o vigor do micélio e com a capacidade de ativar mecanismos fisiológicos, necessários para utilizar os nutrientes do meio de cultura (MATAet al., 2001). Deste modo, as necessidades nutricionais para que o micélio cresça de forma satisfatória, nesta fase inicial do cultivo, pode ser otimizada face o tipo de material utilizado na suplementação do meio de cultivo. Sendo assim, este trabalho teve como objetivo avaliar a produção de biomassa fúngica e crescimento radial da colônia, de três linhagens de P. ostreatus, sobo efeito da adição de farelos em diferentes concentrações ao meio de cultura à base de capim-elefante.

\section{MATERIAL E MÉTODOS}

Os experimentos foram desenvolvidos no Laboratório Experimental de Micologia (LEMICO) do Departamento de Microbiologia e Parasitologia do Instituto de Biologia, da Universidade Federal de Pelotas, RS. Nesteexperimento foram utilizadas as linhagens BF24, DF33 e HF19 de P. ostreatus, oriundas do Módulo de Cogumelos / Faculdade de Ciências Agronômicas da Universidade Estadual Paulista/Campus de Botucatu, Botucatu, SP (MARINO, 2002), depositadas na micoteca do Laboratório Experimental de Micologia do Departamento de Microbiologia e Parasitologia do Instituto deBiologia daUniversidadeFederal dePelotas, Pelotas, RS. Estas linhagens, preservadas em óleo mineral, foram repicadas para meio à base de batata-dextroseágar (BDA) e incubadas a $28^{\circ} \mathrm{C}$ por 10 dias, até serem recuperadas e com crescimento miceliano adequado.

Os experimentos foram realizados separadamente para cada linhagem, utilizando como substrato o capimelefante (Pennisetum sp.), suplementado com 0, 10 e 20\% de farelo de soja, trigo, arroz e milho em relação a sua massa seca, correspondendo a 12 tratamentos.

Folhas e colmo de capim-elefante ( $30 \mathrm{~g})$ adicionado ou não dos farelos foi fervido em $1 \mathrm{~L}$ de água destilada por 30min. e, em seguida, filtrado com o auxílio de um pedaço de gaze e o volume completado para $1 \mathrm{~L}$. Logo após, para o preparo dos meios de cultivo, foram adicionados 15 g. $\mathrm{L}^{-1}$ deágar e 10 g. $\mathrm{L}^{-1}$ dedextrose para posterior esterilização em autoclave por $20 \mathrm{~min}$ a $121^{\circ}$ C.OpHdos meios foi ajustado para 5,5(EIRA\&MINHONI, 1997), sendo depois vertido em placas de Petri previamente esterilizadas $(90 \times 15 \mathrm{~mm})$.

Para a multiplicação das linhagens, foram utilizados discos de cultura, com $10 \mathrm{~mm}$ de diâmetro inoculados nos meios de cultivo suplementados com os farelos (soja, trigo, arroz e milho) nas diferentes concentrações $(0,10$ e $20 \%)$, correspondendo a 12 tratamentos. As placasinoculadasforamincubadas a $28^{\circ}$ Catéobtenção de crescimento para a realização do experimento.

As variáveis analisadas foram: biomassa fúngica e crescimento radial da colônia. $O$ crescimento radial da colônia foi medido através do diâmetro da colônia, com o auxílio de uma régua, em 8 direções ortogonais, a cada $24 \mathrm{~h}$, a partir de $48 \mathrm{~h}$, durante a incubação até o momento queuma colôniaatingiua proximidadedabordada placa emumdostratamentos.Sendo4leituras(aos2,3,4e5dias de incubação) para a linhagem BF24, 3 leituras (aos 2, 3 e 4 dias de incubação) para a linhagem DF33 e 5 leituras (aos 2,3, 4,5e6 dias deincubação) para a linhagem HF19. Apósaúltimaavaliaçãodocrescimento, omeiodecultura foi dissolvido em água fervente, aproximadamente 500 $\mathrm{mL}$.Recolheu-seabiomassafúngicaúmida(Mmu), aqual foi seca em estufa a $50^{\circ} \mathrm{C}$ por $24 \mathrm{~h}$, para a obtenção da biomassa fúngica seca (Mms).

O delineamento experimental foi inteiramente ao acaso com fatorial $\mathrm{A} \times \mathrm{B} \times \mathrm{C}(\mathrm{A}=$ farelo, $\mathrm{B}=$ concentração de farelo $\mathrm{C}=$ período de incubação) para crescimento radial da colônia e $\mathrm{A} \times \mathrm{B}(\mathrm{A}=$ farelo, $\mathrm{B}=$ concentração defarelo) para biomassa fúngica, em cada linhagem. A unidade experimental constou de uma placa de Petri, sendo quatro repetições/tratamento para cada linhagem. Os resultados obtidos foram submetidos à análise da variância e teste de Duncan para comparação das médias, utilizando-se o programa estatístico Sanest.

\section{RESULTADOS E DISCUSSÃO}

Através da análise da variância pode-se observar que para a variável biomassa fúngica houve diferen- 
ças significativas $(\alpha=0,05)$ para e interação entre farelo e concentração de farelo, em todas as linhagens estudadas. A análise das médias de biomassa fúngica, através do teste de Duncan mostrou que apenas os tratamentos com suplementação de farelos de soja e trigo exerceram efeito positivo nas três linhagens de $P$. ostreatus. No entanto, entre os dois farelos destacouse significativamente o de soja nas duas concentrações utilizadas. Para os três isolados, os resultados mais significativos foram obtidos com a adição de farelo de soja a $20 \%$ (Tabela 1 ).

Como observado, o meio de cultivo à base de capim-elefante adicionado de $20 \%$ de farelo de soja promoveu maior biomassa fúngica para todas as linhagens utilizadas. Isso provavelmente ocorreu devido a maior disponibilidade de nitrogênio facilmente assimilável presente neste meio de cultura devido a adição de farelo de soja. De acordo com EIRA \& MinHONI (1997), o farelo de soja contém cerca de $7,38 \%$ de nitrogênio, porcentagem alta quando comparada a dos farelos de trigo $(2,70 \%)$, arroz $(2 \%)$ e milho (1,57\%). JáMAZIERO (1990) citado por ZANETTI\& RANAL (1997) indica que não há uma concordância entre os diferentes autores quanto à concentração ideal de nitrogênio, onde alguns experimentos mostram que há estímulo no crescimento e outros mostram inibição quando é realizada a suplementação com materiais ricos em nitrogênio. De acordo com OliveIRA \&URBEN(2001) o excesso de nitrogênio tende

Tabela 1 - Média de biomassa fúngica (mg) das linhagens BF24, DF33 e HF19 de Pleurotus ostreatus, cultivadas em meios à base de capim-elefante suplementados com farelos de soja, trigo, arroz e milho em diferentes concentrações $(0,10$ e $20 \%)$

\begin{tabular}{llccc}
\hline Farelo & & \multicolumn{3}{c}{ Concentração (\%) } \\
\cline { 3 - 5 } & & 0 & 10 & 20 \\
\hline BF24 & Soja & 10 a C & 23 a B & 37 a A \\
& Trigo & 10 a C & 16 b B & 21 b A \\
& Arroz & 10 a A & 5 c B & 6 c B \\
& Milho & 10 a A & 8 c A & 7 c A \\
DF33 & Soja & 9 a C & 17 a B & 45 a A \\
& Trigo & 9 a B & 21 a A & 21 b A \\
& Arroz & 9 a A & 5 b B & 4 c B \\
& Milho & 9 a A & 4 b B & 9 c A \\
HF19 & Soja & 15 a C & 27 a B & 41 a A \\
& Trigo & 15 a B & 24 a A & 24 b A \\
& Arroz & 15 a A & 8 b A & 9 c A \\
& Milho & 15 a A & 12 b A & 9 c A \\
\hline
\end{tabular}

Médias seguidas de mesma letra minúscula, nas colunas, e maiúscula, nas linhas, não diferem entre si pelo teste de Duncan $(\alpha=0,05)$. Média de quatro repetições. a reprimir a degradação da lignina, retardando ou até inibindo completamente o aparecimento do micélio, o que não ocorreu no presente trabalho, onde a maior biomassa fúngica in vitro foi obtida em meio com a maior concentração de farelo de soja. Petrenko \& BISKO(2004) observaram que a adição de farelo de soja no composto para o cultivo de Agaricus bisporus baixou a relação C/N para 19:1. No presente trabalho, pode se observar que o meio com maior concentração de farelo de soja e, conseqüentemente, com maior disponibilidade de nitrogênio aumentou a biomassa fúngica das linhagens de P. ostreatus.

Através da análise da variância pode-se observar que para a variável crescimento radial da colônia houve diferenças altamente significativas $(\alpha=0,05)$ para a interação entre farelo, concentração de farelo e período de incubação, em todas as linhagens estudadas. A análise das médias de crescimento radial da colônia, através do teste de Duncan, mostrou que na linhagem BF24 os meios à base de 10 e $20 \%$ de farelo de soja e $20 \%$ do farelo de trigo apresentaram melhores resultados. Já para a linhagem DF33, foram superiores os meios adicionados de 10 e $20 \%$ de farelo de soja. Para a linhagem HF19, os meios suplementados de farelo de milho apresentaram diferenças em relação aos demais farelos, mas não diferiram do tratamento sem farelos, assim não estimularam o crescimento (Tabela 2).

Tabela 2 - Média de crescimento radial da colônia (cm) das linhagens BF24 (5 dias de incubação), DF33 (4 dias de incubação) e HF19 (6 dias de incubação) de Pleurotus ostreatus, cultivadas em meios à base de capim-elefante suplementadoscomfarelos desoja, trigo, arrozemilhoem diferentes concentrações $(0,10$ e $20 \%)$

\begin{tabular}{llccc}
\hline Farelo & & \multicolumn{3}{c}{ Concentração (\%) } \\
\cline { 3 - 5 } & & 0 & 10 & 20 \\
\hline BF24 & Soja & 5,12 a B & 6,30 a A & 6,52 a A \\
& Trigo & 5,12 a C & 5,98 b B & 6,31 a A \\
& Arroz & 5,12 a A & 3,82 d B & 3,66 c B \\
& Milho & 5,12 a B & 5,45 c A & 5,08 b B \\
DF33 & Soja & 4,88 a C & 6,17 a B & 6,70 a A \\
& Trigo & 4,88 a B & 5,83 b A & 5,74 b A \\
& Arroz & 4,88 a A & 3,73 d B & 3,77 d B \\
& Milho & 4,88 a A & 4,22 c B & 4,99 c A \\
HF19 & Soja & 6,65 a A & 5,89 b B & $6,50 \mathrm{abA}$ \\
& Trigo & 6,65 a A & 5,95 b B & 6,32 b A \\
& Arroz & 6,65 a A & 4,74 c B & 4,63 c B \\
& Milho & 6,65 a A & 6,70 a A & 6,76 a A \\
\hline
\end{tabular}

Médias seguidas de mesma letra minúscula, nas colunas, e maiúscula, nas linhas, não diferem entre si pelo teste de Duncan $(\alpha=0,05)$. 
Farelo de soja

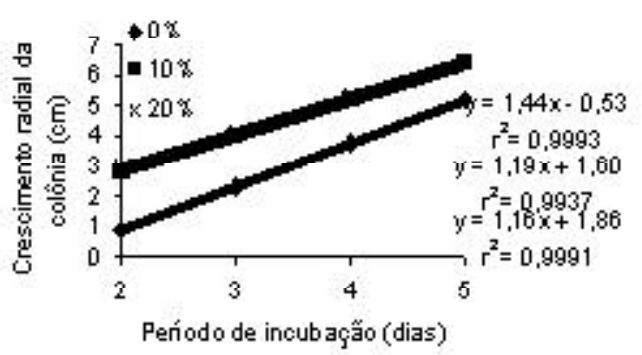

Farelo de arroz

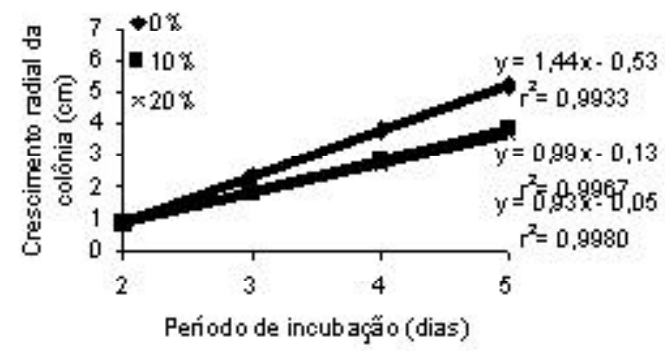

Farelo de trigo

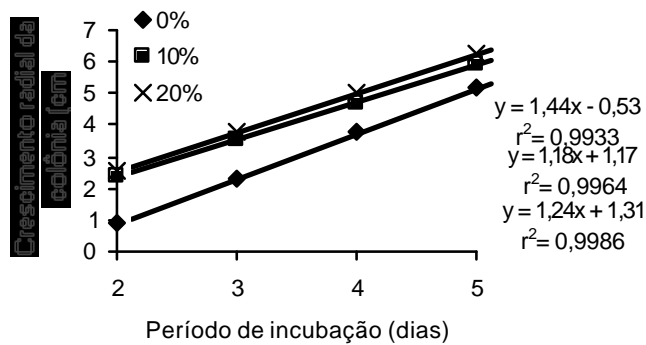

Farelo de milho

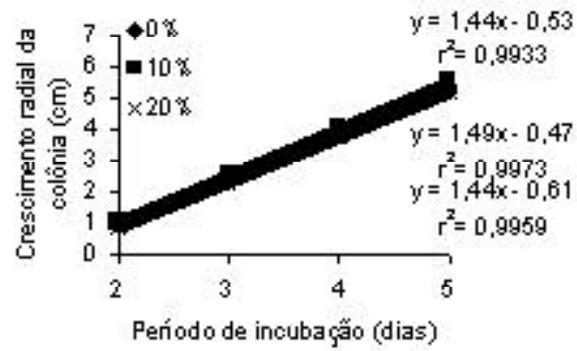

Fig. 1. Crescimento radial da colônia $\left(\mathrm{cm} \cdot \mathrm{dia}^{-1}\right)$ da linhagem BF24 dePleurotusostreatus, cultivada em meios à base decapimelefante suplementados com farelo de soja, trigo, arroz e milho.

Farelo de soja

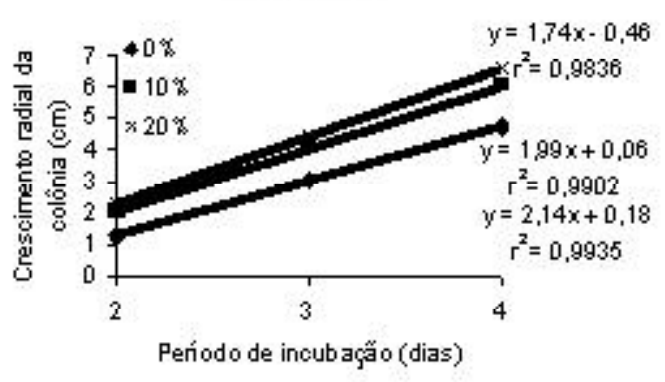

Farelo de arroz

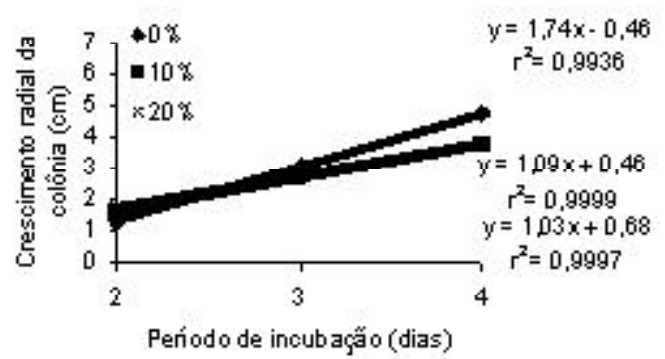

Farelo de trigo

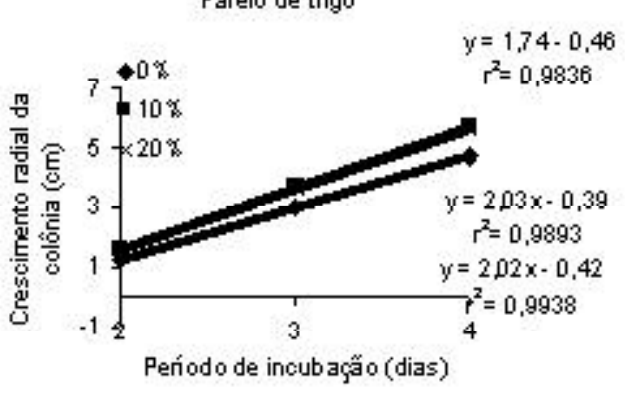

Farelo de milho

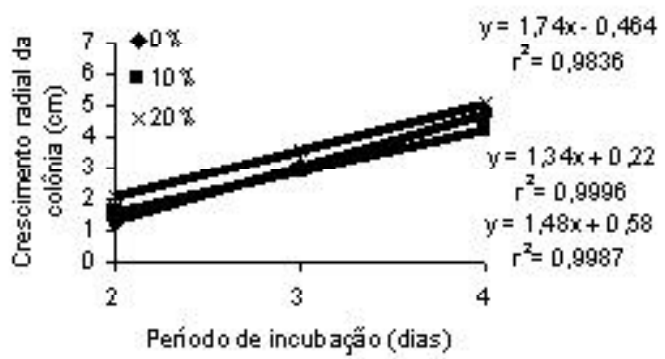

Fig. 2 - Crescimento radial da colônia $\left(\mathrm{cm} \cdot \mathrm{dia}^{-1}\right)$ da linhagem DF33 de Pleurotus ostreatus, cultivada em meios à base de capim-elefante suplementados com farelo de soja, trigo, arroz e milho.

Os dados referentes aocrescimentoradial dacolônia diário das linhagens BF24, DF33 e HF19 foram ajusta- dos a modelos lineares e as equações foram descritas juntamente com as curvas de crescimento $(\alpha=0,05)$. 

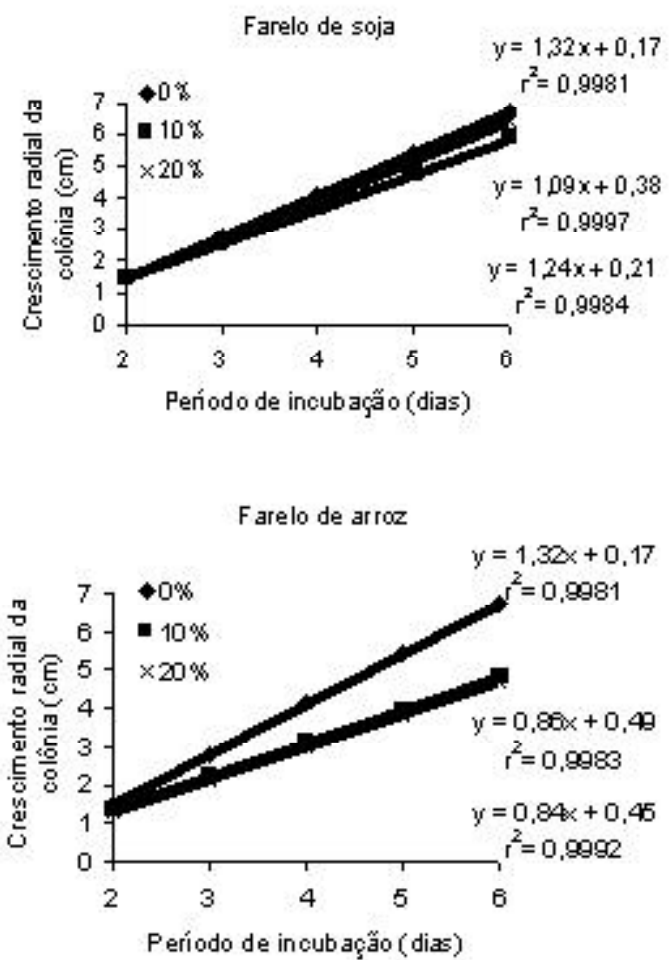

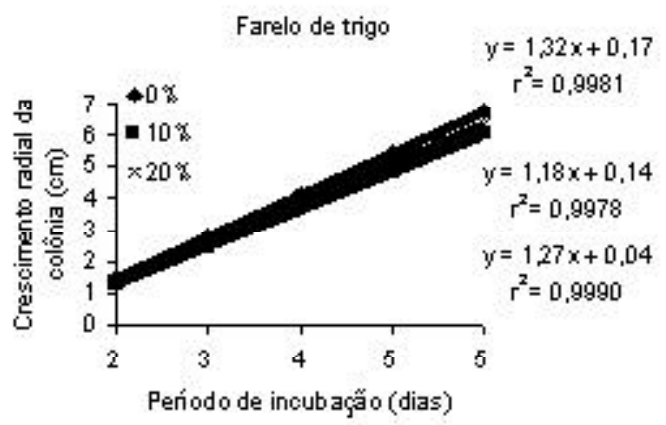

Farelo de milho

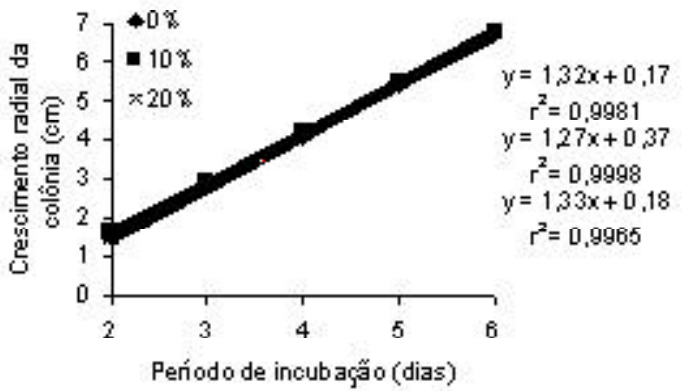

Fig. 3 - Crescimento radial da colônia $\left(\mathrm{cm} \cdot \mathrm{dia}^{-1}\right)$ da linhagem HF19 de Pleurotus ostreatus, cultivada em meios à base de capim-elefante suplementados com farelo de soja, trigo, arroz e milho.

Para a linhagem BF24, o meio de cultura suplementado com farelo de soja mostrou melhor resposta na concentração de $20 \%$, embora, como visto anteriormente, não tenha mostrado diferenças da concentração de $10 \%$ deste farelo. Para o farelo de trigo verificou-se comportamento similar, com a adição de $20 \%$ deste farelo levando a resposta superior no crescimento radial da colônia e diferente de $10 \%$. O farelo de arroz promoveu efeito estimulador inferior ao tratamento sem adição deste farelo. Por último, verificou-se um leve aumento no crescimento radial da colônia, com $10 \%$ de farelo de milho (Fig. 1) (Tabela 2).

A linhagem DF33 mostrou-se mais rápida no desenvolvimento, em relação às demais, completando o crescimento radial da colônia in vitro em quatro dias de incubação. Para esta linhagem, o maior crescimento radial da colônia foi obtido à medida que se aumentou a concentração de farelo de soja. Em relação ao farelo de trigo, a suplementação com $10 \%$ e com $20 \%$ promoveu aumento no crescimento radial da colônia, desde o primeiro dia de incubação até a fase final. Para o farelo de arroz, a adição deste promoveu um leve estímulo no crescimento radial da colônia apenas nos primeiros dias de incubação, não respondendo mais a partir do terceiro dia. Nos primeiros dias de incubação, houve estímulo da suplementação com farelo de milho sobre o crescimento radial da colônia, na fase final, o meio sem a adição de farelos $(0 \%)$ passou a mostrar melhores resultados que os com adição de farelo (Fig. 2). Tendo-se verificado que o meio sem farelo de milho e o com $20 \%$ deste farelo não diferiram entre si (Tabela 2).

A linhagem HF19 foi a que apresentou crescimento do micélio mais lento, em relação às demais linhagens, na velocidade de crescimento, completando sua colonização no sexto dia de incubação. A suplementação do meio de cultivo com farelo de soja não promoveu o mesmo estímulo que o meio sem a adição deste farelo. Comportamento similar ocorreu também nos meios de cultivo suplementados com os farelos de trigo earroz. No entanto, o efeito mais severo ocorreu com farelo de arroz, especialmente, no sexto dia, onde o tratamento sem adição deste farelo promoveu maior velocidade de crescimento. Já, a adição de farelo de milho, não expressou nenhum efeito (Fig. 3).

Conforme analisado, a composição e a quantidade de farelos adicionados ao meio de cultura interferiram na biomassa e no crescimento radial da colônia de P.ostreatus. No meio de cultura a adição de farelos disponibiliza fontes nitrogenadas e estimula a ação enzimática do micélio fúngico em crescimento. Inicialmente, o Pleurotus utilizou os nutrientes facilmente assimiláveis no meio de cultura e quando o micélio 
esgotou estes nutrientes expandiu-se, tornando-se menos denso. De acordo com Regina (2004), o desenvolvimento da habilidade lignocelulítica requer condições nutricionais e culturais, incluindo substrato metabolizável, altos níveis de oxigênio, um limite de nitrogênio e outras condições de cultivo.

Os farelos podem diferir em relação à quantidade de nitrogênio. Entre as quatro fontes utilizadas neste experimento, o de soja e o de milho são, respectivamente, ricos e pobres em nitrogênio, e podem ter cerca de 7,38 e 1,57\% de N (EIRA \& MinHONI, 1997). CRuzetal. (1999), observaram que a utilização de concentrações altas de farelo de aveia proporcionou redução indesejável da taxa de crescimento. Os meios adicionados com farelo de arroz apresentaram, nas linhagens BF24 e DF33 de P. ostreatus, resultados de crescimento radial da colônia inferiores ao meio sem adição de farelo (0\%). O mesmo foi observado por Rossi1' et al. (2003) no cultivo de L. edodes, onde a miceliação diminuiu significativamente com a utilização de proporções crescentes de farelo de arroz.

O farelo de trigo adicionado ao meio de cultura proporcionou resultados superiores aos sem adição deste farelo (0\%) para todas as linhagens BF24 e DF33. De acordo com LABUSCHAGNe $e$ t al. (2000), ao pesquisar P. ostreatus "Florida", observaram que o desenvolvimento micelial desta linhagem apresentou diferenças durante a colonização de palhas de trigo de diferentes variedades, demonstrando haver diferenças nutricionais presentes em substratos da mesma espécie. Resultados que também foram observados por Disset al. (2003), com o efeito negativo quando o farelo de trigo foi adicionado à palha de feijão no cultivo de P. sajor-caju. Já quando o mesmo farelo foi adicionado à palha de milho não houve diminuição do crescimento miceliano. Por outro lado, SiLva (2004) observou que no cultivo de $P$. sajor-caju, ao utilizar meio de cultura à base de serragem de Pinus spp. com 5\% de farelo de trigo eadicionado de outros nutrientes como nitrogênio, manganês, reduziu à metade o tempo de crescimento micelial da linhagem PS2001.

Segundo MARINO (1997), os microrganismos se adaptam aos meios de cultivo em função da disponibilidade de nutrientes e do potencial genético. A autora afirma ainda que o cultivo de diferentes espécies de cogumelos em meios nutricionalmente ricos resultam em isolados mais vigorosos do que em meio pobre. De acordo com Bilay et al. (2000), ao estudarem 30 espécies de cogumelos comestíveis e medicinais, observaram que o tipo de meio utilizado e o $\mathrm{pH}$ influenciam no crescimento miceliano. OHGA \& ROYSE (2004) testaram dois substratos no cultivo de três linhagens de $P$. eryngii. Os autores concluíram que houve aumento máximo de crescimento de $146 \%$, quando utilizaram Cyperus alternifolius como substrato.
Neste trabalho foram observadas médias de crescimento que, de acordo com a linhagem, variaram de 3,6 a 6,5 (BF24), 3,7 a 6,7 (DF33) e 4,6 a 6,7 cm (HF19). MATA et al.(2001), ao estudarem o crescimento micelial de diferentes linhagens L. edodes e L. boryana, emmeios à base de extrato de malte-ágar (MEA) observaram após sete dias de incubação crescimento micelial que variou de 4,9 a 7,1 cm paraL. edodes, e 5,9 a 6,8 cm para L. boryana.

\section{CONCLUSÕES}

De acordo com os resultados obtidos na presente pesquisa sobre o efeito da suplementação do meio de cultivo in vitro para a três linhagens de P. ostreatus, pode-se concluir que o meio de cultivo suplementado com $20 \%$ de farelo de soja favorece o aumento da biomassa fúngica das três linhagensP. ostreatus (BF24, DF33 e HF19) e o crescimento radial da colônia apenas para BF24 e DF33; os farelos de arroz e milho utilizados na suplementação do meio de cultivo não apresentam efeito estimulador para o aumento da biomassa e do crescimento radial da colônia de $P$. ostreatus (linhagens BF24, DF33 e HF19) cultivado in vitro.

\section{REFERÊNCIAS}

BILAY, V.T.; SOlONKO, E.F.; Buchalo, A.S. Growth of edible and medicinal mushrooms on commercial agar media. In: VAN Griensven, L.J.L.D. (Ed.). Science and cultivation of edible fungi. Rotterdam: Balkema, 2000. v.2, p.779-782.

Bonatti, M.;KarnopP, P.;SOARes,H.M.,F URLAN,S.A.Evaluation of Pleurotus ostreatus and Pleurotus sajor-caju nutritional characteristics when cultivated in different lignocellulosic wastes. FoodChemistry, v.88, p.425-428, 2004.

CRUz, O.S.; Castañeda, G.S.;HACh, J.L.P.; Rojas, M.G.; TorReS, E.F. Effect of substrate composition on the mycelial growth of Pleurotus ostreatus. An analysis by mixture and response surface methodologies. Process Biochemistry, v.39, p.127-133, 1999.

Dias, E.S.; Koshikumo, E.M.S.;SchWAN, R.F;SILVA, R. Cultivo do cogumelo Pleurotus sajor-caju em diferentes resíduos agrícolas. Ciência e Agrotecnologia, v.27, n.6, p.13631369, 2003.

EIRA, A.F. \& MinHoni, M.T.A.Manual teórico-prático do cultivo de cogumelos comestíveis. 2.ed. Botucatu: Fundação de Estudos e Pesquisas Agrícolas e Florestais, 1997.115p.

EIRA, A.F.Cultivo do "cogumelo-do-sol" Agaricus blazei(Murrill) ss. Heinemann. Viçosa: Ed. Aprenda Fácil, 2003. 203p.

Jов, D. La utilización de la borra del café como substrato de base para el cultivo de Pleurotus ostreatus (Jacq.: Fr) Kummer. Revista Iberoamaericana de Micologia, v.21, p.195-197, 2004. 
Labuschagne, P.M.; Eicker, A.; Aveling, T.A.S., Meillon, S.; SMith, M.F. Influence of wheat cultivars on straw quality and Pleurotusostreatus cultivation. Bioresource Technology, v.71, p.71-75, 2000.

Mandeel, Q.A.; Al-Laith, A.A.; Mohamed, S.A. Cultivation of oyster mushrooms (Pleurotus spp.) on various lignocellulosic wastes. World Journal of Microbiology \& Biotechnology, v.21, p.601-607, 2005.

Marino, R.H. Produtividade de Pleurotus sajor-caju (Fr.) Sing. em função dos métodos de isolamento e produção de inoculantes. 1997. 134f. Dissertação (Mestrado em Biotecnologia) - Instituto de Química do Campus de Araraquara, Universidade Estadual Paulista, Araraquara, 1997.

Marino, R.H. Melhoramento genético de Pleurotus ostreatus visando o cultivo axênico de linhagens resistentes ao calor. 2002. 109f. Tese (Doutorado em Biotecnologia) - Instituto de Química do Campus de Araraquara, Universidade Estadual Paulista, Araraquara, 2002.

Mata, G.; Delpech, P.; Savoic, J.M. Selection of strains of Lentinula edodes and Lentinula boryana adapted for efficient mycelial growth on wheat straw. Revista Iberoamericana de Micologia, v.18, p.118-122, 2001.

Maziero, R.; Bononi, V.L.; CAPELARI, M.; Cultivo e produtividade de Pleurotusostreatus var. Florida em Mogi das Cruzes, Brasil. Hoehnea, v.19, n.1/2, p.1-7, 1992.

ModA, E.M.; HorII, J.; Spoto, M.H.F. Edible mushroom Pleurotus sajor-caju production on washed and supplemented sugarcane bagasse. Scientia Agricola, v.62, p.127-132, 2005.

Ohga, S. \& RoYse, D.J. Cultivation of Pleurotus eryngii on umbrella plant (Cyperusalternifolius) substrate. Journal Wood Science, v.50, p.466-469, 2004.

Oliveira, H.C.B. \& Urben, A.F. Cultivo de Pleurotus sp. utilizando a técnica "Jun-Cao". In:URBEN, A.F.Produção de cogumelos por meio da tecnologia chinesa modificada. Brasília: Embrapa Recursos Genéticos e Biotecnologia, 2001.151p.

Petrenko, B.F. \& Bisko, N.A. Influence of the addition of soybean supplements to the compost on the yield of Agaricus bisporus. In:RoMAINERINKER, C.P. (Ed.). Science and cultivation of edible fungi. Rotterdam: Balkema, 2004. v.1, p.353-357.

Rajarathnam, S.; Shashirekha, M.N.; Bano, Z. Biodegradation of gossypol by the white oyster mushroom, Pleurotus florida, during culturing on rice straw growth substrate, supplemented with cottonseed powder. World Journal of Microbiology \& Biotechnology, v.17, n. 221-227, 2001.

Regina, M.Atividade de enzimaslignocelulíticas nocrescimento de Lentinula edodes em subprodutos energéticos. 2004. 86f. Tese (Doutorado em Agronomia) - Faculdade de Ciências Agronômicas, Universidade Estadual Paulista, Botucatu, 2004.

Rossi, I.H.; Monteiro, A.C.; Machado, J.O. Desenvolvimento micelial de Lentinula edodes como efeito da profundidade e suplementação do substrato. Pesquisa Agropecuária Brasileira, v.36, n.6, p.887-891, 2001.

Rossi, I.H.; Monteiro, A.C.; Machado, J.O.; Barbosa, J.C. Supplementation of sugarcane bagasse with rice bran and sugarcane molasses for shiitake (Lentinulaedodes) spawn production. Brazilian Journal of Microbiology, v.34, p.61-65, 2003.

Silva, S.M. Formulação de meios de crescimento para o cultivo sólido de Pleurotus sajor-caju, à base de serragem de Pinus spp. 2004.95f.Dissertação(Mestradoem Biotecnologia) - Instituto de Biotecnologia, Universidade de Caxias do Sul, Caxias do Sul, 2004.

Urben, A.F.; UriartT, A.H. Princípios docultivo de cogumelos pela técnica "Jun-Cao". In:URBEN, A.F. Produçãode cogumelos por meio da tecnologia chinesa modificada.Brasília: Embrapa Recursos Genéticos e Biotecnologia, 2001.151p.

WANG, D.; SAKODA, A.; SuZUKI, M. Biological efficiency and nutritional value of Pleurotus ostreatus cultivated on spent beer grain. Bioresource Technology, v.78, p.293300, 2001.

Wisbeck, E. Estudo do cultivo submerso de Pleurotus ostreatus DSM 1833 para a produção de biomassa e de exopolissacarídeos. 2003. 196f. Tese (Doutorado Engenharia Química) - Universidade Federal de Santa Catarina, Florianópolis, 2003.

Zanetti, A.L. \& Ranal, M.A. Suplementação da cana-deaçúcar com guandu no cultivo de Pleurotus sp. 'Florida'. Pesquisa Agropecuária Brasileira, v.32, n.9, p.959964, 1997.

Recebido em 20/2/06

Aceito em 31/8/06 